Tricarbonylchromium Complexes of Centropolyindans, $3^{[1]}$

\title{
Synthesis and Structural Investigation of Tricarbonylchromium Mono-, Bis-, and Tris-Complexes of Triptindan ${ }^{\text {h }}$
}

\author{
Alberto Ceccon ${ }^{a} *$, Alessandro Gambaro ${ }^{a}$, Francesco Manoli ${ }^{\mathrm{b}}$, Alfonso Venzo ${ }^{b}$, Paolo Ganis ${ }^{\mathrm{c}}$, Giovanni Valle ${ }^{\mathrm{d}}$, and \\ Dietmar Kuck ${ }^{\text {* }}$
}

Dipartimento di Chimica Fisica, Università di Padova ${ }^{a}$,

Via Loredan 2, I-35131 Padova, Italy

CNR, Centro di Studio sugli Stati Molecolari, Radicalici ed Eccitati ${ }^{\text {b }}$,

Via Loredan 2, I-35131 Padova, Italy

Dipartimento di Chimica, Università di Napoli ${ }^{c}$,

Via Mezzocannone 4, I-80134 Napoli, Italy

CNR, Centro di Studio sui Biopolimeri ${ }^{\mathrm{d}}$,

Via Marzolo, 3, 35131 Padova, Italy

Fakultät für Chemie, Universität Bielefeld ${ }^{e}$,

Universitätsstraße 25, D-33501 Bielefeld 1, Germany

Received December 30, 1992

Key Words: Polycyclic compounds / Centropolyindans / Chromium arene complexes / Stereochemistry

The reaction of $9 H, 10 H-4 \mathrm{~b}, 9 \mathrm{a}([1,2]$ benzenomethano)indeno[1,2a] indene (triptindan, TRIP) with $\mathrm{Cr}(\mathrm{CO})_{6}$ in $\mathrm{Bu}_{2} \mathrm{O} / \mathrm{THF}(9: 1)$ affords a monocomplex (A) together with two bis- $\mathrm{Cr}(\mathrm{CO})_{3}$ complexes (B and $\mathbf{C}$ ) and one tris- $\mathrm{Cr}(\mathrm{CO})_{3}$ complex (D). The relative yields of the four complexes as well as their tendency to lose $\mathrm{Cr}(\mathrm{CO})_{3}$ are related to stabilizing intramolecular factors. All the $\mathrm{Cr}(\mathrm{CO})_{3}$ units of the complexes $\mathrm{A}, \mathrm{B}$, and D are coordinated in the isoclined orientation with respect to the polar axis of the ligand, whereas complex $\mathbf{C}$ bears one isoclined and one anticlined $\mathrm{Cr}(\mathrm{CO})_{3}$ unit. The results of X-ray measurements support the hypothesis of weak attractive electronic interactions bonds between the oxygen atoms of the carbonyl groups and polarized faces of benzene rings.
In continuation of our research on the chemistry of centropolyindan- $\mathrm{Cr}(\mathrm{CO})_{3}$ complexes ${ }^{[1]}$ we have synthesized and characterized a series of tricarbonylchromium complexes of $9 H, 10 H-4 b, 9 \mathrm{a}([1,2]$ benzenomethano)indeno[ $[1,2-a]$ indene, the so-called triptindan ${ }^{[2]}$. The complexation of centropolyindan ligands ${ }^{[3]}$ with $\mathrm{Cr}(\mathrm{CO})_{3}$ leads to a number of stereoisomers the relative yields of which are strongly controlled by steric effects. In this regard, we have already investigated the case of $4 b, 5,9 a, 10$-tetrahydroindeno[2,1-a]indene (DIN) ${ }^{[1]}$, arising from the formal condensation of two indan units, and the case of 10-methyltribenzotriquinacene (MTBT) $)^{[4,5]}$, derived from a threefold spherical condensation (Scheme 1). Both of these hydrocarbons are bent polyarene molecules with nonequivalent complexation sites at the concave and/or the convex side of the ligand where the number of isomers is determined by the possibility of syn-anti stereoisomerism.

An axial condensation of three indan units leads to the formation of the propellor-shaped molecule of triptindan (TRIP) ${ }^{[6]}$ with $C_{3}$ symmetry. In this case, the molecular geometry arising from its polar ternary axis together with severe conformational and steric requirements present in the ligand itself ${ }^{[7]}$ can induce either an isoclined or an anticlined complexation of $\mathrm{Cr}(\mathrm{CO})_{3}$ with the indan unit. Moreover, in principle, because of the particular geometry of the ligand mol-
Scheme 1. Centropolyindan ligands
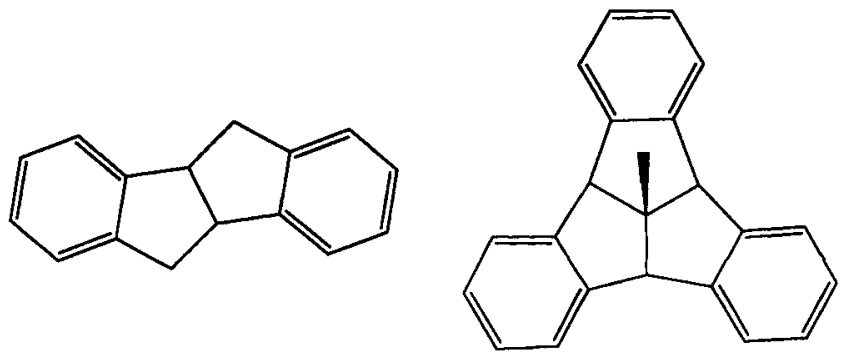

DIN

MTBT

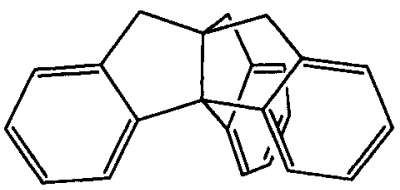

TRIP

ecule, the interactions between $\mathrm{Cr}(\mathrm{CO})_{3}$ groups and the $\pi$ electron system of an adjacent arene ring may be investigated. 
The crystal and molecular structures reported in this paper will show how the conformational aspects are responsible both for the synthetic course and the chemical properties of the $\mathrm{Cr}(\mathrm{CO})_{3}$ complexes of TRIP.

\section{Syntheses}

The $\mathrm{Cr}(\mathrm{CO})_{3}$ complexes of TRIP were obtained according to the procedure described previously ${ }^{[1,4]}$. By working with an excess of the complexing agent and prolonged reaction times (Table 1, runs 1 and 2) we achieved a high conversion (ca. $80 \%$ ) of the arene reagent into four different complexes which were isolated as yellow crystalline air-stable solids.

Scheme 2. Orientation of the $\mathrm{Cr}(\mathrm{CO})_{3}$ units in the $\mathrm{Cr}(\mathrm{CO})_{3}$-complexed triptindans
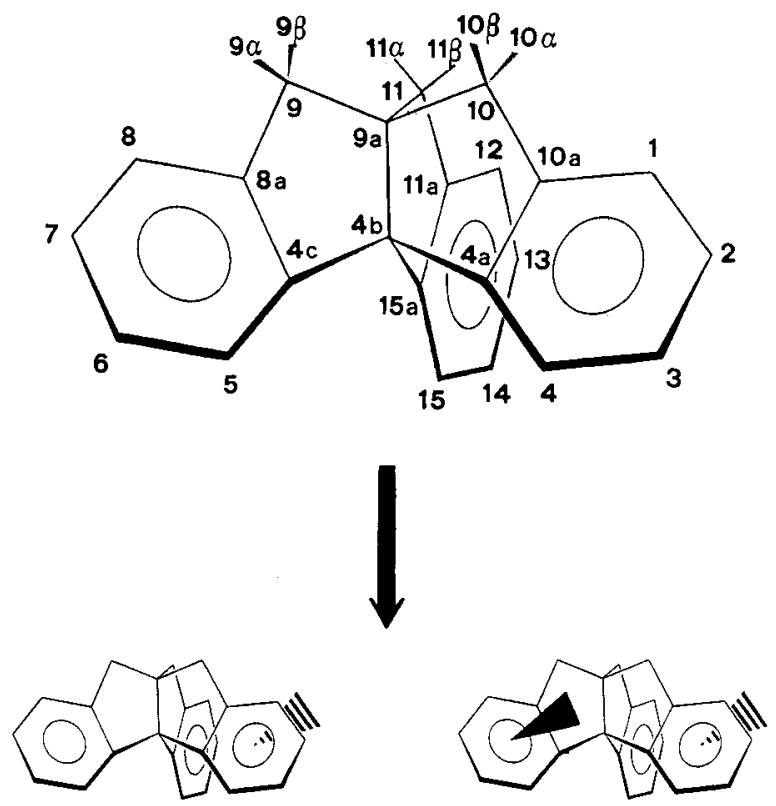

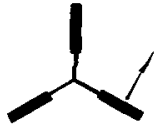

A
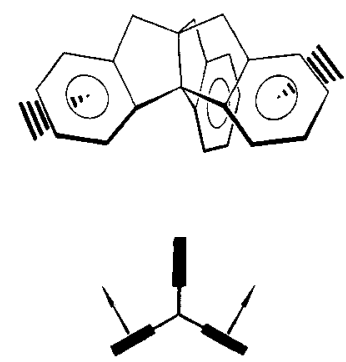

C
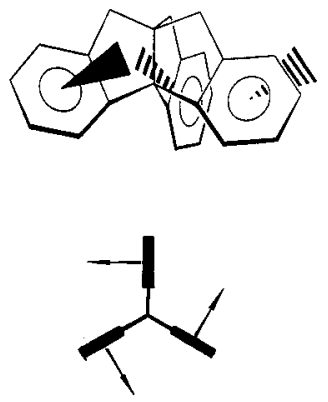

On the basis of their mass spectra (see Experimental) and of NMR and X-ray crystallographic measurements (see below), they were identified as the complexes A-D (Scheme 2). The isolated yields of the complexes in the runs 1 and 2, carried out under similar experimental conditions, are quite reproducible; among the bis-complexes, the formation of $\mathbf{B}$, the unsymmetrical isomer, is highly favored with respect to that of $\mathbf{C}$, the symmetrical one, the yield of which is even lower than that of the tris-complexed species, $\mathbf{D}$.

In run 3, the mono-metallic complex $\mathbf{A}$ was treated with a $60 \%$ molar excess of $\mathrm{Cr}(\mathrm{CO})_{6}$ [i. e., $0.8 \mathrm{~mol}$ of $\mathrm{Cr}(\mathrm{CO})_{6}$ per free ring of $\mathbf{A}]$. After heating at reflux temperature for $17 \mathrm{~h}$, the conversion of the reagent into bis- and tris-complexed species is modest $(17 \%)$ and the ratio $\mathbf{B} / \mathbf{C}$ parallels that obtained in runs 1 and 2 . Only minor quantities of $\mathbf{D}$ were observed owing to the low molar ratio $\mathrm{A} / \mathrm{Cr}(\mathrm{CO})_{6}$.

Finally, the bis-complex $\mathbf{B}$, in the presence of a large excess of $\mathrm{Cr}(\mathrm{CO})_{6}$, was converted $(40 \%$ after $48 \mathrm{~h})$ to the triscomplexed species $\mathbf{D}$, and no isomerization to the other biscomplex $\mathbf{C}$ was observed.

Table 1. Complexation products of free and $\mathrm{Cr}(\mathrm{CO})_{3}$-complexed triptindan ${ }^{[a]}$

\begin{tabular}{llllcllll}
\hline Run & Substrate & $\begin{array}{l}\mathrm{Cr}(\mathrm{CO})_{3} / \\
\text { substrate } \\
\text { (moles) }\end{array}$ & $\begin{array}{l}\text { Reaction } \\
\text { time }[\mathrm{h}]\end{array}$ & $\begin{array}{c}\% \\
\text { Conversion }\end{array}$ & & $\%$ & Yield \\
\hline 1 & TRIP & $3.6: 1$ & 24 & 78 & 66 & 23 & 4.5 & 6.5 \\
2 & TRIP & $3.6: 1$ & 38 & 88 & 61 & 20 & 2.5 & 17 \\
3 & A & $1.6: 1$ & 17 & 17 & & 84 & 9.5 & 8.5 \\
4 & B & $4: 1$ & 48 & 40 & & & & 100 \\
\hline
\end{tabular}

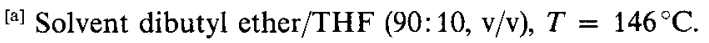

In order to obtain a qualitative indication of the lability of the $\mathrm{Cr}(\mathrm{CO})_{3}$ group in the different complexes, we heated the substrates $\mathbf{A}-\mathbf{D}$ in decaline at $150^{\circ} \mathrm{C}$ in the presence of a large excess (50 times, or more) of hexamethylbenzene as a $\mathrm{Cr}(\mathrm{CO})_{3}$ scavenger. Even after prolonged heating, the exchange product $\mathrm{Cr}(\mathrm{CO})_{3}-\mathrm{C}_{6} \mathrm{Me}_{6}$ was not observed: conversely, the different complexes manifest different tendencies to lose $\mathrm{Cr}(\mathrm{CO})_{3}$ in such a medium likely according to a dissociative pathway. The monocomplex $\mathbf{A}$ was recovered unchanged even after heating for $24 \mathrm{~h}$. The two bis-complexes show a different behaviour: $\mathbf{B}$ was found to dissociate to $\mathbf{A}$ in about one hour, whereas $\mathbf{C}$ did so in few minutes showing a pronounced instability at high temperatures. Finally, the tris-complex $\mathbf{D}$ was converted in one hour to $\mathbf{B}$ which subsequently gives $\mathbf{A}$.

\section{NMR Measurements}

The ${ }^{1} \mathrm{H}$ - (see Figure 1) and ${ }^{13} \mathrm{C}-\mathrm{NMR}$ spectra of $\mathbf{A}-\mathbf{D}$ have been used for identification. The proton assignments given in Table 2 were performed by means of selective decoupling and ${ }^{1} \mathrm{H}\left\{{ }^{1} \mathrm{H}\right\}$ NOE measurements. The spectra of the aliphatic moiety of the molecules are shown in Figure 2. The ${ }^{13} \mathrm{C}-\mathrm{NMR}$ resonances (Table 3 ) were attributed to the 

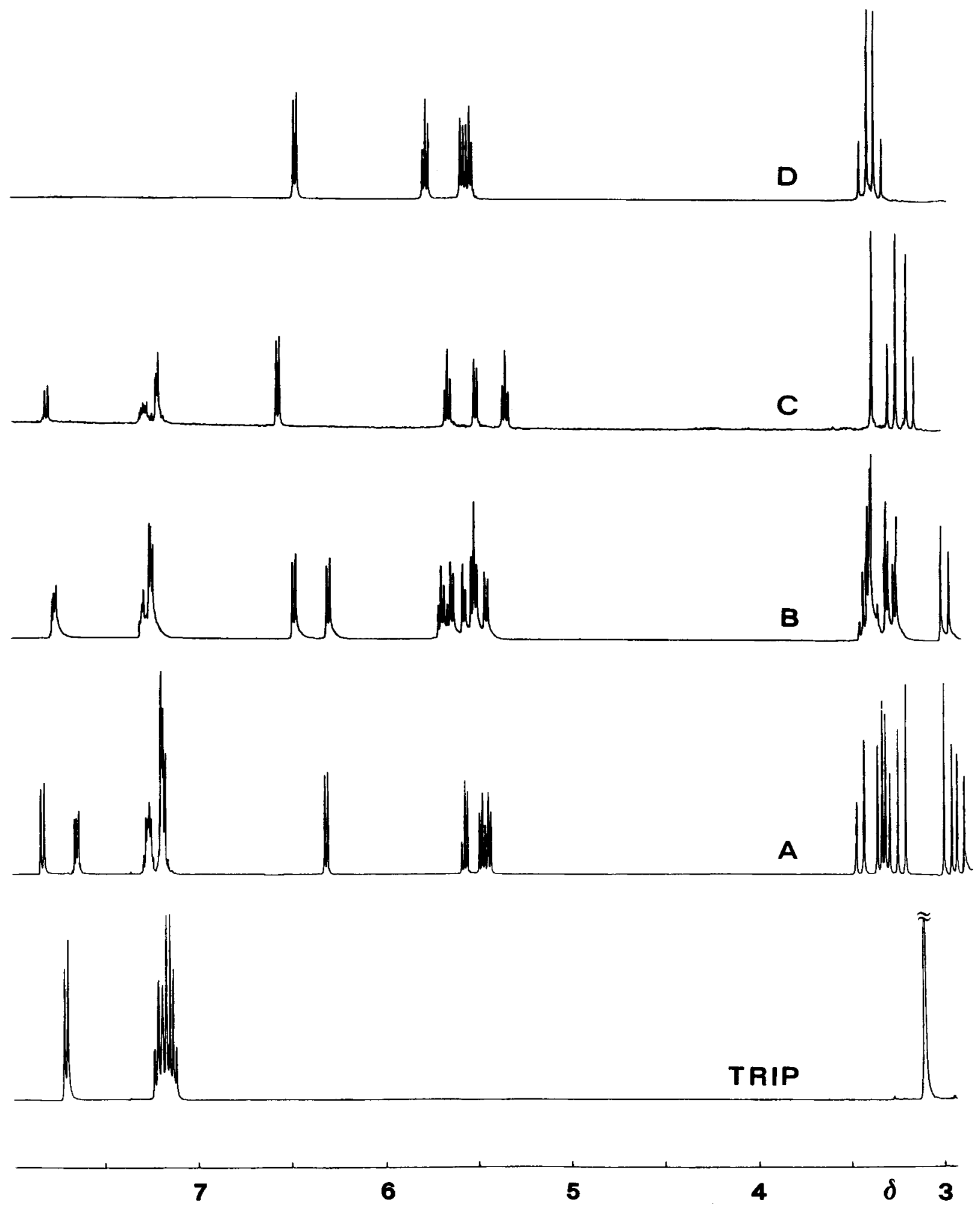

Figure 1. ${ }^{1} \mathrm{H}$-NMR spectra of TRIP and of the $\mathrm{Cr}(\mathrm{CO})_{3}$-complexed TRIP's $\left(v_{0}=400.13 \mathrm{MHz}\right.$; solvent $\left[\mathrm{D}_{6}\right]$ acetone; $T=298 \mathrm{~K}$; internal reference $\mathrm{Me}_{4} \mathrm{Si}$ )

corresponding nuclei by selective proton decoupling experiments and partially relaxed spectra.

Ligand: The ${ }^{1} \mathrm{H}-\mathrm{NMR}$ spectrum of TRIP confirms the equivalence of the three indan moieties. It exhibits an ABCD pattern due to the aromatic protons in the range $\delta=$
$7.7-7.1$, together with a singlet at $\delta=3.10$ due to the methylene protons. NOE measurements allow the assignment of all arene proton resonances and corroborate the lowest field signal at $\delta=7.70$ to be due to $4-\mathrm{H}, 5-\mathrm{H}$, and 15-H. The pronounced deshielding of the ortho protons of 

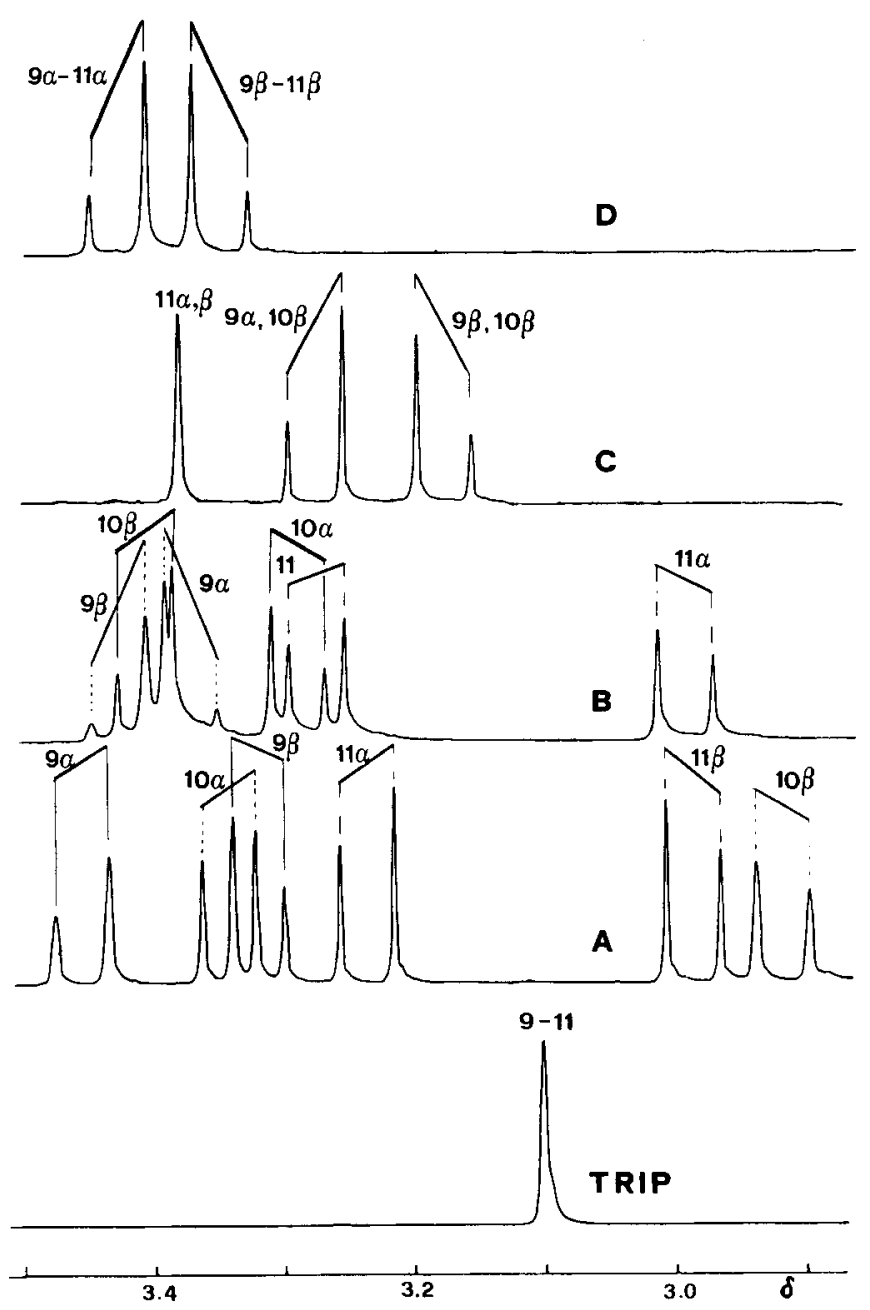

Figure 2. High-field portion of the ${ }^{\prime} \mathrm{H}-\mathrm{NMR}$ spectra of TRIP and of the complexes A-D. For experimental conditions, see Figure 1

the diphenylmethane subunits by the opposite arene ring is a common feature in the ${ }^{1} \mathrm{H}-\mathrm{NMR}$ spectra of all the centropolyindans and their derivatives reported in this paper and in refs. ${ }^{[1,4-8]}$.

Monocomplex A: By complexation of one benzene ring with $\mathrm{Cr}(\mathrm{CO})_{3}$ the molecular symmetry of the ligand is removed. The effect of the complexation on the chemical shifts is sufficient to render the resonance signals of both the aromatic and the aliphatic moieties of the monocomplex distinguishable (see Figure 2); thus, they can be assigned by
Table 3. ${ }^{13} \mathrm{C}$-NMR chemical shifts values ${ }^{[a]}$ of the free and $\mathrm{Cr}(\mathrm{CO})_{3^{-}}$ complexed triptindan

\begin{tabular}{lccccc}
\hline & TRIP & A & B & C & D \\
\hline C(1A-3A $)$ & - & 233.84 & 233.61 & 233.84 & 233.69 \\
C(10) & 44.12 & 42.98 & 43.81 & 44.81 & 45.81 \\
$\mathrm{C}(10 \mathrm{a})$ & 143.67 & 116.03 & 116.06 & 117.73 & 116.20 \\
$\mathrm{C}(1)$ & 124.83 & 88.99 & 96.42 & 88.12 & 88.48 \\
$\mathrm{C}(2)$ & 127.75 & 91.95 & 91.55 & 96.55 & 97.84 \\
$\mathrm{C}(3)$ & 127.91 & 95.52 & 96.42 & 93.53 & 91.26 \\
$\mathrm{C}(4)$ & 125.84 & 91.42 & 89.07 & 89.87 & 91.46 \\
$\mathrm{C}(4 \mathrm{a})$ & 146.46 & 119.97 & 118.93 & 120.23 & 118.44 \\
$\mathrm{C}(4 \mathrm{~b})$ & 77.76 & 76.81 & 75.85 & 72.73 & 74.97 \\
$\mathrm{C}(1 \mathrm{~B}-3 \mathrm{~B})$ & - & - & 233.84 & 233.61 & 233.69 \\
$\mathrm{C}(4 \mathrm{c})$ & 146.46 & 145.38 & 118.93 & 120.23 & 118.44 \\
$\mathrm{C}(5)$ & 125.84 & 126.09 & 91.96 & 89.87 & 91.46 \\
$\mathrm{C}(6)$ & 127.91 & 127.33 & 91.55 & 93.53 & 91.26 \\
$\mathrm{C}(7)$ & 127.75 & 128.79 & 96.42 & 96.55 & 97.84 \\
$\mathrm{C}(8)$ & 124.83 & 124.29 & 89.07 & 88.12 & 88.48 \\
$\mathrm{C}(8 \mathrm{a})$ & 143.67 & 143.10 & 116.06 & 117.73 & 116.20 \\
$\mathrm{C}(9)$ & 44.12 & 45.95 & 43.81 & 44.81 & 45.81 \\
$\mathrm{C}(9 \mathrm{a})$ & 63.91 & 62.28 & 60.84 & 63.70 & 59.65 \\
$\mathrm{C}(1 \mathrm{C}-3 \mathrm{C})$ & - & - & - & - & 233.69 \\
$\mathrm{C}(11)$ & 44.12 & 45.03 & 44.74 & 45.30 & 45.81 \\
$\mathrm{C}(11 \mathrm{a})$ & 143.67 & 143.18 & 142.53 & 141.82 & 116.20 \\
$\mathrm{C}(12)$ & 124.83 & 124.54 & 123.93 & 125.36 & 88.48 \\
$\mathrm{C}(13)$ & 127.75 & 128.53 & 129.50 & 129.20 & 97.84 \\
$\mathrm{C}(14)$ & 127.91 & 128.31 & 128.10 & 127.94 & 91.26 \\
$\mathrm{C}(15)$ & 125.84 & 126.32 & 126.63 & 127.81 & 91.46 \\
$\mathrm{C}(15 \mathrm{a})$ & 146.46 & 146.12 & 145.17 & 144.24 & 118.44 \\
\hline & & & & &
\end{tabular}

${ }^{[a]}$ Internal standard $\mathrm{Me}_{4} \mathrm{Si}$; solvent $\left[\mathrm{D}_{6}\right]$ acetone; $T=298 \mathrm{~K}$. For carbon numbering of complexes, see Scheme 2 .

means of careful decoupling and NOE experiments. In particular, the ${ }^{1} \mathrm{H}-\mathrm{NMR}$ spectrum of $\mathbf{A}$ consists of an ABCD system showing a complicated resonance pattern at $\delta=$ 7.83, 7.2-7.3, and 7.19 (integral ratio $1: 2: 1$ ) attributed to the $15-\mathrm{H}, 13,14-\mathrm{H}$, and $12-\mathrm{H}$ protons, respectively. Another $\mathrm{ABCD}$ pattern belonging to the protons of the other uncomplexed ring is found at $\delta=7.64$ and $7.25-7.15$, respectively (integral ratio $1: 3$ ), and is attributed to the $5-\mathrm{H}$ and 6,7,8-H protons. Finally, a clearly resolved $\mathrm{ABCD}$ spin system appears between $\delta=6.32$ and 5.48 due to the hydrogen atoms of the coordinated ring. The signals due to the methylene protons appear as three distinct AB spin systems in the range of $\delta=3.45-2.92$, as expected owing to the presence of the $\mathrm{Cr}(\mathrm{CO})_{3}$ moiety, and the assignments

Table 2. ${ }^{1} \mathrm{H}-\mathrm{NMR}$ chemical shift values ${ }^{[a]}$ of the free and $\mathrm{Cr}(\mathrm{CO})_{3}$-complexed triptindan

\begin{tabular}{|c|c|c|c|c|c|c|c|c|c|c|c|c|c|c|c|}
\hline \multicolumn{2}{|c|}{ Comp'd $10 \alpha-\mathrm{H}^{[\mathrm{b}]}$} & \multirow{2}{*}{$\frac{10 \beta-\mathrm{H}^{[\mathrm{b}]}}{3.10}$} & \multirow{2}{*}{\multicolumn{3}{|c|}{$\frac{1-\mathrm{H} \quad 2-\mathrm{H} \quad 3-\mathrm{H}}{7.10-7.25}$}} & \multirow{2}{*}{$\frac{4-\mathrm{H}}{7.70}$} & \multicolumn{2}{|c|}{$9 \alpha-\mathrm{H} 9 \beta-\mathrm{H} 8-\mathrm{H}$} & \multirow{2}{*}{$\frac{\mathrm{I} 7-\mathrm{H} 6-\mathrm{H}}{7.10-7.25}$} & \multirow{2}{*}{$\frac{5-\mathrm{H}}{7.70}$} & \multicolumn{5}{|c|}{$11 \alpha-\mathrm{H} 11 \beta-\mathrm{H} 12-\mathrm{H} 13-\mathrm{H} 14-\mathrm{H} 15-\mathrm{H}$} \\
\hline TRIP & 3.10 & & & & & & 3.10 & 3.10 & & & 3.10 & 3.10 & & -7.25 & 7.70 \\
\hline $\mathbf{A}$ & 3.34 & 2.92 & 5.48 & 5.58 & 5.54 & 6.32 & 3.45 & 3.32 & $7.23-7.16$ & 7.64 & 3.23 & 2.99 & 7.19 & -7.3 & 7.83 \\
\hline B & 29 & 3.41 & 5.56 & 5.64 & 5.51 & 6.47 & 3.38 & 3.425 & 5.695 .51 & 6.29 & 2.99 & 3.28 & 7.28 & & 7.75 \\
\hline C & 28 & 3.18 & 5.50 & 5.65 & 5.34 & 6.56 & 3.28 & 3.18 & $5.65 \quad 5.34$ & 6.56 & 3.38 & 3.38 & 7.20 & $7.20-7.35$ & 7.80 \\
\hline D & 3.42 & 3.35 & 5.58 & 5.78 & 5.54 & 6.58 & 3.42 & $3.35 \quad 5.58$ & $\begin{array}{l}3 \\
5.78 \quad 5.54\end{array}$ & 6.58 & 3.42 & 3.35 & 5.58 & $5.78 \quad 5.54$ & 6.58 \\
\hline
\end{tabular}

${ }^{[a]}$ Internal standard $\mathrm{Me}_{4} \mathrm{Si}$; solvent $\left[\mathrm{D}_{6}\right]$ acetone; $T=298 \mathrm{~K}$. For proton numbering, see Scheme $2 .-{ }^{[b]}$ For the assignment of the methylene protons, see text. 
were accomplished by NOE measurements. The number of signals in the proton-decoupled ${ }^{13} \mathrm{C}-\mathrm{NMR}$ spectrum is consistent with the absence of molecular symmetry in this complex. The CO chemical shift value $(\delta=233.84)$ is very close to those found for the same nuclei belonging to $\mathrm{Cr}(\mathrm{CO})_{3}$ units coordinated to the concave side of a bent polyindan molecule ${ }^{[1,4]}$.

Bis-complexes B and $\mathbf{C}$ : In the ${ }^{1} \mathrm{H}-\mathrm{NMR}$ spectrum of the first eluted bis-complexed triptindan, $\mathbf{B}$, two distinct $\mathrm{ABCD}$ systems are found in the range of $\delta=6.47-5.45$. Correspondingly, a single ABCD pattern is observed between $\delta=$ 7.75 and 7.10 due to the protons of the uncomplexed ring. Moreover, the methylene group resonances appear as three distinct $\mathrm{AB}$ spin systems. As expected, all the 23 carbon nuclei resonances of the organic moiety appear well resolved in the ${ }^{13} \mathrm{C}$-NMR spectrum, and two different signals for the $\mathrm{CO}$ carbons are also observed at $\delta=233.61$ and 233.84, respectively. The absence of molecular symmetry confirms that in $\mathbf{B}$ the two metal moieties are coordinated to the ligand in such a way that one $\mathrm{Cr}(\mathrm{CO})_{3}$ unit is directed towards the back side of the other coordinated ring, and the other metal group towards the uncoordinated benzene ring, as shown in Scheme 2.

In contrast, the proton and carbon NMR spectra of $\mathbf{C}$ show the presence of two equivalent $\mathrm{Cr}(\mathrm{CO})_{3}$-coordinated benzene rings, as indicated by the single $A B C D$ pattern for the eight aromatic protons occurring between $\delta=6.56$ and 5.34, together with another $\mathrm{ABCD}$ spin system in the range of $\delta=7.80-7.20$ belonging to the four protons of the uncoordinated ring. Furthermore, two methylene resonance

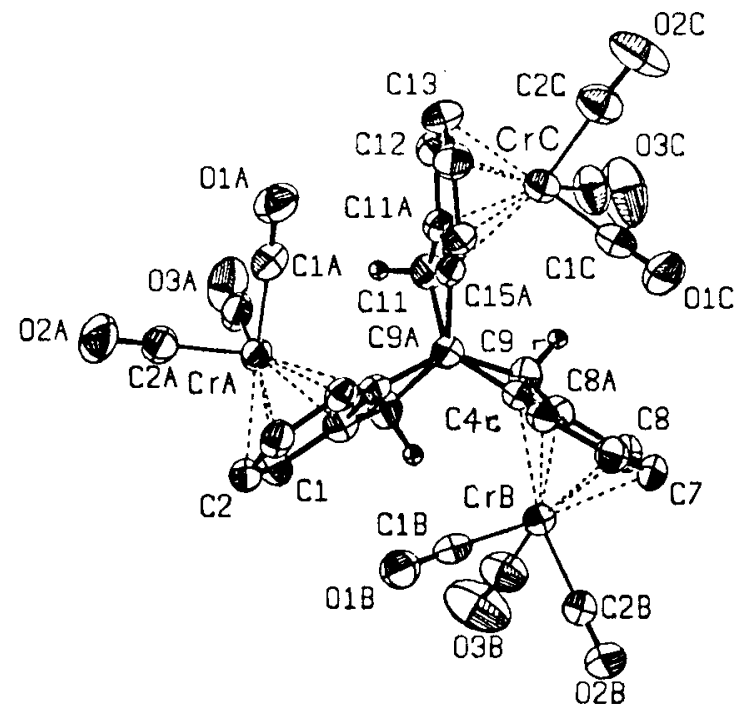

Figure 3. Projection of the molecule $\mathbf{D}$ as viewed along the $\mathrm{C} 9 \mathrm{a}-\mathrm{C} 4 \mathrm{~b}$ bond. Significant distances $[\AA]$ : M(1A) $\cdots 11 \beta-\mathrm{H} 2.79$, $\mathrm{M}(1 \mathrm{~B}) \cdots 10 \beta-\mathrm{H} \quad 2.94, \mathbf{M}(1 \mathrm{C}) \cdots 9 \beta-\mathrm{H} 2.94$ [M(1A), M(1B), and M(1C) designate the location of the middle points of the $\mathrm{C}(1 \mathrm{~A}) \equiv \mathrm{O}(1 \mathrm{~A}), \mathrm{C}(1 \mathrm{~B}) \equiv \mathrm{O}(1 \mathrm{~B})$, and $\mathrm{C}(1 \mathrm{C}) \equiv \mathrm{O}(1 \mathrm{C})$ groups bound to $\mathrm{Cr}(\mathrm{A}), \mathrm{Cr}(\mathrm{B})$, and $\mathrm{Cr}(\mathrm{C})$, respectively]. Significant torsion angles $\left[{ }^{\circ}\right]$ : $\mathrm{C}(\mathrm{A})-\mathrm{Cr}(\mathrm{A})-\mathrm{P}(\mathrm{A})-\mathrm{C} 4 \mathrm{a}-43, \mathrm{C}(2 \mathrm{~A})-\mathrm{Cr}(\mathrm{A})-\mathrm{P}(\mathrm{A})-\mathrm{C} 3-42$, $\mathrm{C}(3 \mathrm{~A})-\mathrm{Cr}(\mathrm{A})-\mathrm{P}(\mathrm{A})-\mathrm{C} 1-42, \mathrm{C}(\mathrm{BB})-\mathrm{Cr}(\mathrm{B})-\mathrm{P}(\mathrm{B})-\mathrm{C} 4 \mathrm{c}-43$, $\mathrm{C}(2 \mathrm{~B})-\mathrm{Cr}(\mathrm{B})-\mathrm{P}(\mathrm{B})-\mathrm{C} 6-41, \quad \mathrm{C}(3 \mathrm{~B})-\mathrm{Cr}(\mathrm{B})-\mathrm{P}(\mathrm{B})-\mathrm{C} 8-29$, $\mathrm{C}(1 \mathrm{C})-\mathrm{Cr}(\mathrm{C})-\mathrm{P}(\mathrm{C})-\mathrm{C}-15 \mathrm{a}-44, \quad \mathrm{C}(2 \mathrm{C})-\mathrm{Cr}(\mathrm{C})-\mathrm{P}(\mathrm{C})-\mathrm{C} 14$ $-42, \quad \mathrm{C}(3 \mathrm{C})-\mathrm{Cr}(\mathrm{C})-\mathrm{P}(\mathrm{C})-\mathrm{C} 12-42, \mathrm{C} 10-\mathrm{C} 9 \mathrm{a}-\mathrm{C} 4 \mathrm{~b}-\mathrm{C} 4 \mathrm{a}$

$-15[P(A), P(B)$, and $P(C)$ designate the location of the centers of the benzene rings bound to $\operatorname{Cr}(\mathrm{A}), \mathrm{Cr}(\mathrm{B})$, and $\mathrm{Cr}(\mathrm{C})$, respectively] patterns are observed, one $\mathrm{AB}$ spin system $(\delta=3.28$ and $3.18)$ corresponding to the two equivalent methylene groups of the coordinated indan moieties, and a singlet $(\delta=3.38)$ corresponding to the methylene protons of the uncoordinated one. In addition, only one signal for the $\mathrm{CO}$ carbon atoms is found in the ${ }^{13} \mathrm{C}-\mathrm{NMR}$ spectrum at $\delta=233.61$. These observations indicate the presence of an apparent symmetry plane containing the uncomplexed indan unit: the $\mathrm{Cr}(\mathrm{CO})_{3}$ units are bound to geometrically equivalent sides of the organic ligands so that both the inorganic tripods are directed towards the uncoordinated benzene ring, as depicted in Scheme 2. NOE measurements allow the high-field portion of the $\mathrm{AB}$ spin system to be attributed to the protons in the syn position with respect to the $\mathrm{Cr}(\mathrm{CO})_{3}$ groups $(9 \beta$ $\mathrm{H}$ and $10 \alpha-\mathrm{H})$, i. e., to those pointing towards the uncomplexed indan unit.

Tris-complex D: The symmetry of the unique tris-complexed triptindan is confirmed by the NMR data. In fact, the proton and carbon spectra of $\mathbf{D}$ show the presence of three equivalent $\mathrm{Cr}(\mathrm{CO})_{3}$-coordinated benzene rings, as indicated by the single ABCD pattern for the aromatic protons occurring in the range of $\delta=6.58-5.54$, together with a single $\mathrm{AB}$ pattern at $\delta=3.42$ and 3.35 , due to the methylene groups. Only one signal for the $\mathrm{CO}$ carbon atoms is found in the ${ }^{13} \mathrm{C}$-NMR spectrum at $\delta=233.69$.

\section{X-Ray Measurements}

Suitable crystals for diffractometric analysis were obtained by slow concentration in an inert atmosphere of concentrated solutions of $\mathbf{B}, \mathbf{C}$, or $\mathbf{D}$ in acetone/methanol/dichloromethane $(1: 1: 1)$. No single crystals could be obtained

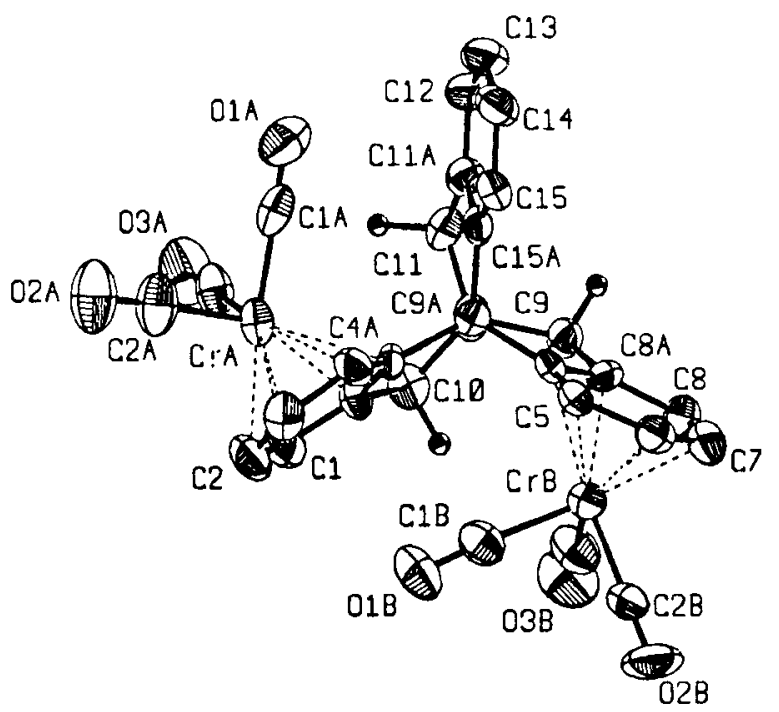

Figure 4. Projection of the molecule $B$ as viewed along the $C 9 a-$ $\mathrm{C} 4 \mathrm{~b}$ bond. Significant distances $[\AA]: \quad \mathbf{M}(1 \mathrm{~A}) \cdots 11 \beta-\mathrm{H} \quad 3.04$ $\mathrm{M}(1 \mathrm{~B}) \cdots 10 \beta-\mathrm{H} 2.92[\mathrm{M}(1 \mathrm{~A})$ and $\mathrm{M}(1 \mathrm{~B})$ designate the location of the middle points of the $C(1 \mathrm{~A}) \equiv \mathrm{O}(1 \mathrm{~A})$ and $\mathrm{C}(1 \mathrm{~B}) \equiv \mathrm{O}(1 \mathrm{~B})$ groups bound to $\operatorname{Cr}(A)$ and $\operatorname{Cr}(B)$, respectively]. Significant torsion angles $\left.{ }^{\circ}\right]: \quad \mathrm{C}(1 \mathrm{~A})-\mathrm{Cr}(\mathrm{A})-\mathrm{P}(\mathrm{A})-\mathrm{C} 4 \mathrm{a}-33, \mathrm{C}(2 \mathrm{~A})-\mathrm{Cr}(\mathrm{A})-\mathrm{P}(\mathrm{A})-\mathrm{C} 3$ $-33, \mathrm{C}(3 \mathrm{~A})-\mathrm{Cr}(\mathrm{A})-\mathrm{P}(\mathrm{A})-\mathrm{C} 1-32, \mathrm{C}(\mathrm{B})-\mathrm{Cr}(\mathrm{B})-\mathrm{P}(\mathrm{B})-\mathrm{C} 4 \mathrm{c}$ $-27, \quad \mathrm{C}(2 \mathrm{~B})-\mathrm{Cr}(\mathrm{B})-\mathrm{P}(\mathrm{B})-\mathrm{C} 6-29, \quad \mathrm{C}(3 \mathrm{~B})-\mathrm{Cr}(\mathrm{B})-\mathrm{P}(\mathrm{B})-\mathrm{C} 8$ $-29, \mathrm{C} 10-\mathrm{C} 9 \mathrm{a}-\mathrm{C} 4 \mathrm{~b}-\mathrm{C} 4 \mathrm{a}-18[\mathrm{P}(\mathrm{A})$ and $\mathrm{P}(\mathrm{B})$ designate the location of the centers of the benzene rings bound to $\operatorname{Cr}(A)$ and $\mathrm{Cr}(\mathrm{B})$, respectively] 


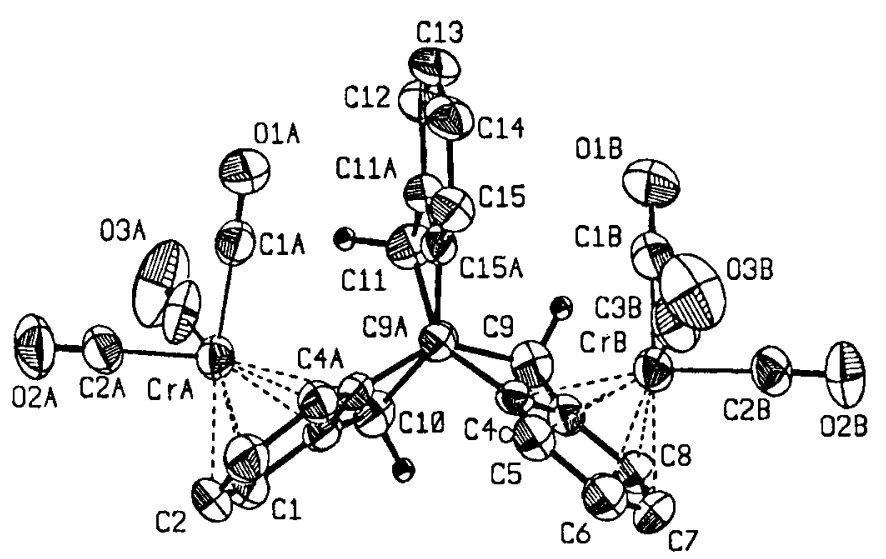

Figure 5. Projection of the molecule $C$ as viewed along the $\mathrm{C} 9 \mathrm{a}-\mathrm{C} 4 \mathrm{~b}$ bond. Significant distances $[\AA]$ : $\mathrm{M}(1 \mathrm{~A}) \cdots 11 \beta-\mathrm{H} 2.90$; $\mathrm{M}(1 \mathrm{~B}) \cdots 9 \beta-\mathrm{H} 2.87[\mathrm{M}(1 \mathrm{~A})$ and $\mathrm{M}(1 \mathrm{~B})$ designate the location of the middle points of the $C(1 \mathrm{~A}) \equiv \mathrm{O}(1 \mathrm{~A})$ and $\mathrm{C}(1 \mathrm{~B}) \equiv \mathrm{O}(1 \mathrm{~B})$ groups bound to $\mathrm{Cr}(\mathrm{A})$ and $\mathrm{Cr}(\mathrm{B})$, respectively]. Significant torsion angles $\left[^{\circ}\right]: \quad \mathrm{C}(1 \mathrm{~A})-\mathrm{Cr}(\mathrm{A})-\mathrm{P}(\mathrm{A})-\mathrm{C} 4 \mathrm{a}-34, \mathrm{C}(2 \mathrm{~A})-\mathrm{Cr}(\mathrm{A})-\mathrm{P}(\mathrm{A})-\mathrm{C} 3$ $-37, \mathrm{C}(3 \mathrm{~A})-\mathrm{Cr}(\mathrm{A})-\mathrm{P}(\mathrm{A})-\mathrm{C} 1-34, \mathrm{C}(\mathbf{B})-\mathrm{Cr}(\mathrm{B})-\mathrm{P}(\mathrm{B})-\mathrm{C} 4 \mathrm{c}$ +23, $\mathrm{C}(2 \mathrm{~B})-\mathrm{Cr}(\mathrm{B})-\mathrm{P}(\mathrm{B})-\mathrm{C} 6+26, \quad \mathrm{C}(3 \mathrm{~B})-\mathrm{Cr}(\mathrm{B})-\mathrm{P}(\mathrm{B})-\mathrm{C} 8$ $+25, \mathrm{C} 10-\mathrm{C} 9 \mathrm{a}-\mathrm{C} 4 \mathrm{~b}-\mathrm{C} 4 \mathrm{a}-18[\mathrm{P}(\mathrm{A})$ and $\mathrm{P}(\mathrm{B})$ designate the location of the centers of the benzene rings bound to $\operatorname{Cr}(\mathrm{A})$ and $\mathrm{Cr}(\mathrm{B})$, respectively]

from solutions of $\mathbf{A}$ in the above-mentioned and other similar solvent mixtures.

The X-ray analyses are in agreement with the spectroscopic identification of the complexes and provide detailed insights into intramolecular interactions between the various indan subunits and the inorganic moieties.

The molecular structure of the tris-complex $\mathbf{D}$ obtained by $\mathrm{X}$-ray analysis is shown in Figure 3, those of the isomeric bis-complexes $\mathbf{B}$ and $\mathbf{C}$ are reported in Figures 4 and 5 , respectively. In complex $B$ the two $\mathrm{Cr}(\mathrm{CO})_{3}$ units are bound to equivalent sides of the organic ligand in an isoclined configuration. In contrast, in $\mathbf{C}$ the two metal groups are bound to non-equivalent sides of the ligand, one in the isoclined and the other in the anticlined configuration. Crystal data and details of the intensity data collection for complexes $\mathbf{B}, \mathbf{C}$, and $\mathbf{D}$ are reported in Table 4 .

\section{Discussion}

Complex D shows a pseudo-ternary symmetry; its polar pseudo-ternary axis has no simple relation with the crystallograhic axes. The conformation of the ligand is almost completely rigid except for the allowed small rotation $\sigma$ about the central bond $\mathrm{C}(4 \mathrm{~b})-\mathrm{C}(9 \mathrm{a})$ of the three indan moieties. Actually, we have found sigma $|\sigma|=15^{\circ}$; this torsion is required in order to bring about a common puckered conformation for all the three joined five-membered rings and to relieve strong repulsive interactions between the methylene hydrogen atoms. Similar effects have been reported previously for the free triptindan ligand ${ }^{[76,9]}$ and are observed quite generally for centropolyindans ${ }^{[3,9,10]}$. The molecule of the ligand assumes a propellor-shaped conformation in either of the two right- or left-handed enantiomers. For such a structure, therefore, the two faces of the benzene rings are geometrically non-equivalent, since they are turned upwards and downwards with respect to the polar pseudo-ternary axis. Thus, the complexation with three $\mathrm{Cr}(\mathrm{CO})_{3}$ units could produce two quite different isomers both retaining the imposed pseudo-ternary symmetry. Any other tris-complexed isomer is sterically forbidden.

The isomer found in this structural analysis is shown in Figure 3. It is likely the most stable one, as inferred below. All of the three $\mathrm{Cr}(\mathrm{CO})_{3}$ units are oriented with respect to the indan moieties in the usual, more stable exo conformation; a rotation of $9-14^{\circ}$ about the chromium-arene bond from the idealized staggered conformation is observed. For all of the three $\mathrm{Cr}(\mathrm{CO})_{3}$ units it is evident that one carbonyl (or, more exactly, its oxygen atom) is located very close to the central normal to the vicinal benzene ring on the uncomplexed side at a distance from its plane of ca. $3.10-3.20 \AA$. Similar features with even shorter distances $(2.9-3.0 \AA)$ have already been found in related complexes $^{[1,4]}$; they are explained in terms of weak bonding interactions. We believe that such a conformation can neither be casual nor merely due to packing reasons. Moreover, for all of the three $\mathrm{Cr}(\mathrm{CO})_{3}$ units it is found that the middle point of one $\mathrm{CO}$ bond lies at a distance of ca. $2.8-2.9 \AA$ from one methylene hydrogen atom of the vicinal indan group. This fact has been suggested to be a further stabilizing feature ${ }^{[1,4]}$, in spite of the presence of a slight "slippage" $(0.04-0.05 \AA)$ of the $\operatorname{Cr}(\mathrm{CO})_{3}$ units towards the outermost carbon atoms of the bound benzene rings.

The molecular structure of B entirely resembles the common moiety present in complex $\mathbf{D}$, including the torsion angle $|\sigma|=18^{\circ}$. The two $\operatorname{Cr}(\mathrm{CO})_{3}$ units still assume the favored staggered exo conformation. The deviation from the idealized staggered conformation is even smaller here and ranges within $2-3^{\circ}$. Short distances between the middle point of the carbonyl groups and the methylene hydrogens within $2.9-3.1 \AA$ give rise to the characteristic feature already mentioned for $\mathbf{D}$. Two oxygen atoms of the $\mathrm{Cr}(\mathrm{CO})_{3}$ units are located near the central normal to the vicinal benzene rings, but $\mathrm{O}(1 \mathrm{~B})$ approaches an already complexed benzene ring at a distance from its plane of ca. $3.08 \AA$, while $\mathrm{O}(1 \mathrm{~A})$ lies at the larger distance of $3.18 \AA$ from the uncomplexed ring (see Figure 4).

In complex $\mathbf{C}$ (Figure 5), the conformation of the ligand is almost exactly the same as in $\mathbf{D}$ as shown by the torsion angle $\sigma$ about the junction bond of the three indan moieties $\left(|\sigma| \approx 18^{\circ}\right)$. In this complex, the two $\operatorname{Cr}(\mathrm{CO})_{3}$ units occupy non-equivalent faces of the benzene rings. Therefore, we have the possibility of comparing the conformations preferred in the two cases. The $\operatorname{Cr}(\mathrm{A})(\mathrm{CO})_{3}$ species shows a conformation almost identical with those of the $\mathrm{Cr}(\mathrm{CO})_{3}$ units of $\mathbf{B}$ and $\mathbf{D}$; it is practically staggered exo, the deviation from the idealized staggered conformation amounts to ca. $5-6^{\circ}$. One oxygen atom $[\mathrm{O}(1 \mathrm{~A})]$ lies very close to the central normal to the non-complexed benzene ring at a distance from its plane of ca. $3.1 \AA$; the middle point of the carbonyl bond $\mathrm{C}(3 \mathrm{~A}) \equiv \mathrm{O}(3 \mathrm{~A})$ is at $2.9 \AA$ from $11 \beta-\mathrm{H}$. In contrast to this, the $\mathrm{Cr}(\mathrm{B})(\mathrm{CO})_{3}$ species displays a quite different conformation. It adopts the uncommon and less stable staggered endo conformation with a deviation from the idealized 
staggered orientation of ca. $5^{\circ}$. Still, an oxygen atom [O(1B)] lies near the central normal to the uncomplexed benzene ring even though at a much greater distance (ca. $3.40 \AA$ ) from its plane, and a short distance from the middle point of the $\mathrm{C}(1 \mathrm{~B}) \equiv \mathrm{O}(1 \mathrm{~B})$ bond to $9 \beta-\mathrm{H}$ of $2.9 \AA$ is still observed. These two last features are to some extent preserved to the detriment of the more stable and usual exo conformation of the $\mathrm{Cr}(\mathrm{CO})_{3}$ unit, thus confirming their important stabilizing role for all these complexes. For both of the $\mathrm{Cr}(\mathrm{CO})_{3}$ units, a slight slippage is observed as found in $\mathbf{B}$ and $\mathbf{D}$. Nonetheless, all this implies, for the case of $\mathbf{C}$, an overall labile structure as proved by the facile decomplexation of this species (see above) and is in line with its lower stability as compared to $\mathbf{D}$ and $\mathbf{B}$.

Table 4. Summary of crystal and intensity data collection for complexes $\mathbf{B}, \mathbf{C}$, and $\mathbf{D}$

\begin{tabular}{|c|c|c|c|}
\hline & $\mathbf{B}$ & $\mathbf{C}$ & $\mathbf{D}$ \\
\hline Formula & $\mathrm{C}_{29} \mathrm{H}_{18} \mathrm{Cr}_{2} \mathrm{O}_{6}$ & $\mathrm{C}_{29} \mathrm{H}_{18} \mathrm{Cr}_{2} \mathrm{O}_{6}$ & $\mathrm{C}_{32} \mathrm{H}_{18} \mathrm{Cr}_{3} \mathrm{O}_{12}$ \\
\hline $\mathbf{M}$ & 566.45 & 566.45 & 702.48 \\
\hline Colour & yellow needles & yellow needles & yellow needles \\
\hline Crystal dim./mm & $.30 \times 0.15 \times 0.20$ & $0.25 \times 0.20 \times 0.20$ & $0.20 \times 0.20 \times 0.15$ \\
\hline $\mathrm{T} / \mathrm{K}$ & $298 \pm 1$ & $298 \pm 1$ & $298 \pm 1$ \\
\hline Radiation & \multicolumn{3}{|c|}{ graphite-monochromated Mo-K $\mathrm{K}_{\alpha}(\lambda=0.7107 \AA)$} \\
\hline Space group & $\mathrm{P} 2_{1} / \mathrm{n}$ & $\mathrm{P} 21_{1} / \mathrm{c}$ & $\mathrm{P} 21 / \mathrm{n}$ \\
\hline $\mathrm{a} / \AA$ & $19.025(9)$ & $16.794(8)$ & $17.020(8)$ \\
\hline $\mathrm{b} / \AA$ & $9.947(5)$ & $9.942(5)$ & $20.355(9)$ \\
\hline$c / \AA$ & $12.882(6)$ & $14.264(6)$ & $8.112(5)$ \\
\hline$\beta /^{\circ}$ & $92.5(1)$ & $93.4(2)$ & $98.6(1)$ \\
\hline $\mathrm{V} / \AA^{3}$ & 2435.49 & 2377.41 & 2778.74 \\
\hline $\mathrm{Z}$ & 4 & 4 & 4 \\
\hline $\mathrm{D}_{c} / \mathrm{g} \mathrm{cm}^{-3}$ & 1.54 & 1.58 & 1.68 \\
\hline $\mathbf{F}(000)$ & 1151.95 & 1415.92 & 1151.95 \\
\hline$\mu / \mathrm{cm}^{-1}$ & 11.69 & 10.63 & 15.27 \\
\hline Scan speed/deg $\min ^{-1}$ & \multicolumn{3}{|c|}{2.0 in the $2 \theta$ scan mode } \\
\hline Scan width/deg & 1.2 & 1.2 & 1.2 \\
\hline Take off angle/deg & 3.0 & 3.0 & 3.0 \\
\hline $2 \theta$ range & \multicolumn{3}{|c|}{$3.0 \leq 2 \theta \leq 45$} \\
\hline Readen reflections & 6025 & 6560 & 5950 \\
\hline Extincted reflections & 504 & 538 & 213 \\
\hline Reflections used for refinement & $\mathrm{nt}^{[\mathrm{a}]} \quad 1729$ & 3248 & 2362 \\
\hline Solution methods & Patterson & Patterson & Patterson \\
\hline Hydrogen atoms detected & 9 of 18 & 11 of 18 & 10 of 18 \\
\hline Refined parameters & 334 & 334 & 397 \\
\hline $\mathrm{R}^{[\mathrm{b}]}\left(\right.$ on $\left.\mathrm{F}_{0}\right)$ & 0.056 & 0.044 & 0.041 \\
\hline $\mathrm{R}_{\mathrm{W}}[\mathrm{c}]$ & 0.060 & 0.044 & 0.045 \\
\hline Goodness of fit ${ }^{[a]}$ & 1.120 & 1.315 & 1.244 \\
\hline Highest map residuals, $\mathrm{e} / \AA^{3}$ & 0.53 & 0.56 & 0.27 \\
\hline
\end{tabular}

${ }^{\text {[a] }} F_{\mathrm{o}}^{2} \geq 2 \sigma\left(F_{\mathrm{o}}^{2}\right) .-{ }^{\text {[b] }} R=\sum\left\|F_{\mathrm{o}}|-| F_{\mathrm{c}}\right\| / \Sigma\left|F_{\mathrm{o}}\right| \cdot-{ }^{\left[{ }^{[\mathrm{cl}}\right]} R_{w}=$ $\left[\Sigma w\left(\left|F_{\mathrm{o}}\right|-\left|F_{\mathrm{c}}\right|\right)^{2} / \Sigma w F_{\mathrm{o}}^{2}\right]^{1 / 2} .-{ }^{[\mathrm{d}]} \mathrm{GOF}=\left[\Sigma w\left(\left|F_{\mathrm{o}}\right|-\left|F_{\mathrm{c}}\right|\right)^{2} \mid\right.$ $\left.(\mathrm{NO}-\mathrm{NV})^{2}\right]^{1 / 2}$.

\section{Conclusions}

Treatment of triptindan with $\mathrm{Cr}(\mathrm{CO})_{6}$ in $\mathrm{Bu}_{2} \mathrm{O} / \mathrm{THF}$ (9:1) gives one monocomplexed and a unique tris-complexed species together with two bis-complexed molecules. The relative yields of the four complexes and their different tendencies to lose the metal are clearly related to stabilizing intramolecular factors. These four structures, together with other similar ones already published ${ }^{[1,4]}$, offer an interesting set of cases in which it is possible to study the recurrent feature of carbonyl oxygen atoms located on the central normal to arene groups at relatively short distances from their planes. As a matter of fact we note that, in general, this distance is in the range of $2.9-3.1 \AA$ if the arene ring is bound to a $\mathrm{Cr}(\mathrm{CO})_{3}$ unit as well, and it increases to $3.2-3.3 \AA$ if the arene moiety is uncoordinated. In the particular case of the bis-complexed triptindan $\mathbf{C}$, we observe still another situation. Here, the anticlined $\mathrm{Cr}(\mathrm{CO})_{3}$ group faces an uncomplexed arene ring, which, however, is backed by the second $\mathrm{Cr}(\mathrm{CO})_{3}$ unit. By adopting the unusual endo conformation, the tripod still orients one of its carbonyl groups towards the central normal of that arene ring, even though at a larger $\mathrm{O} \cdots$ arene distancee of $3.4-3.5 \AA$. These facts seem to support the hypothesis of weak bonding between oxygen atoms and polarized faces of benzene rings in terms of attractive electronic interactions between the hybrid $\mathrm{CO}$ orbitals and the $\pi$ system of the involved benzene ring.

This work was supported in part by the National Research Council of Italy (CNR) through its "Centro di Studio sugli Stati Molecolari, Radicalici ed Eccitati". Support by the Deutsche Forschungsgemeinschaft (DFG, Ku $6631-2$ ) is gratefully acknowledged.

\section{Experimental}

All reactions and manipulations of the complexes were performed in an oxygen-free Ar atmosphere. The solvents were carefully dried and deoxygenated before use, and the $\mathrm{Cr}(\mathrm{CO})_{6}$ reagent (Aldrich) was sublimed twice under reduced pressure just prior to use. Solvent mixtures, reaction times, and substrate/complexing agent ratios are given in Table 1. The percentages of complexation products were determined by integration of the corresponding signals in the ${ }^{1} \mathrm{H}$ NMR spectra of the crude reaction mixtures. In the preparative experiments, the pure products were obtained by flash chromatography of the residue on silica after removal of the solvents. All complexes were obtained as yellow, air-stable microcrystalline powders. - Melting points are uncorrected. - IR: Perkin-Elmer 580 B, THF solutions. - MS (70 eV): Vacuum Generators VG $16 \mathrm{Mi}$ cro-Mass. Microanalyses were performed by Mr. L. Turiaco, Dipartimento di Chimica Inorganica, Metallorganica ed Analitica, Università di Padova. - The ${ }^{1} \mathrm{H}$ - and ${ }^{13} \mathrm{C}-\mathrm{NMR}$, including ${ }^{1} \mathrm{H}$ homodecoupling and ${ }^{1} \mathrm{H}\left\{{ }^{1} \mathrm{H}\right\}$ NOE experiments: Bruker AM 400 spectrometer (400.1 MHz), nearly saturated solutions (2-10 mmol $\mathrm{dm}^{-3}$ ) of carefully dried, oxygen-free $\left[\mathrm{D}_{6}\right]$ acetone. Proton-decoupled ${ }^{13} \mathrm{C}$-NMR spectra $(100.6 \mathrm{MHz})$ were obtained by using a $6 \mathrm{~s}-$ delayed Waltz-like CPD decoupling technique with full recover of the Overhauser line enhancement. Owing to the low solubility of the complexes, $1028-2056$ accumulations were required to obtain a satisfactory signal-to-noise ratio for non-quaternary carbon nuclei. For quaternary carbon atoms, in particular for C-4b, longer delay times (typically 30-60 s) and reduced flip angle impulses (typically $30^{\circ}$ ) were used. 
Collection of X-Ray Diffraction Data: Single crystals of $\mathbf{B}, \mathbf{C}$, and D were grown under argon from carefully dried, oxygen-free solutions of acetone/methanol/dichloromethane (1:1:1). Standard centering and autoindexing procedures (Philips PW-100 computercontrolled four-circle diffractometer, graphite monochromator) indicated primitive monoclinic lattices $P 2_{1} / n(\mathbf{B}$ and $\mathbf{D})$ and $P 2 / c(\mathbf{C})$. Orientation matrix and unit cell dimensions from 25 symmetryrelated reflections; intensity correction for Lorentz and polarization effects. A unitary weighting scheme was used. Crystal data and details of intensity data are compiled in Table 4. Further details of the crystal structure investigations are available on request from the Fachinformationszentrum Karlsruhe, Gesellschaft für wissenschaftlich-technische Information $\mathrm{mbH}$, D-76344 EggensteinLeopoldshafen, on quoting the depository number CSD-57297, the names of the authors, and the journal citation.

$\{9 H, 10 H-4 b, 9 a-([1,2]$ Benzenomethano $)$ indenol 1,2-a]indene $\}$ tricarbonylchromium (A): M.p. $219-220^{\circ} \mathrm{C}$ (dec.). - IR (THF): $\tilde{v}=$ $1964 \mathrm{~cm}^{-1}$ (vs), 1895 (vs), 1880 (vs, CO). - MS, $m / z$ (\%): 430 (7.5) $[\mathrm{M}]^{\circ+}, 374(8.2)\left[\mathrm{M}-2 \mathrm{CO}^{+}, 346(100)\left[\mathrm{M}-3 \mathrm{CO}^{+}, 294\right.\right.$ (6.8) $[\mathrm{M}-(\mathrm{Cr}, 3 \mathrm{CO})]^{\cdot+}, 52(32.4)[\mathrm{Cr}]^{+} .-\mathrm{C}_{26} \mathrm{H}_{18} \mathrm{CrO}_{3}$ (430.4): calcd. C 72.55, H 4.22; found C 72.6, H 4.20.

$\{9 H, 10 H-4 b, 9 a-([1,2]$ Benzenomethano $)$ indeno[1,2-a Jindene $\}$ $\alpha, \alpha$-bis (tricarbonylchromium) (B): M.p. $210-212^{\circ} \mathrm{C}$ (dec.). - IR (THF): $\tilde{\mathrm{v}}=1964 \mathrm{~cm}^{-1}$ (vs), 1891 (vs), 1888 (vs, CO). - MS, $m / z$ (\%): $566(6.1)[\mathrm{M}]^{*+}, 510(2.0)[\mathrm{M}-2 \mathrm{CO}]^{+}, 482(11.6)[\mathrm{M}-$ $3 \mathrm{CO}^{*+}, 454(11.6)[\mathrm{M}-4 \mathrm{CO}]^{+}, 430$ (6.8) $[\mathrm{M}-(\mathrm{Cr}$, $3 \mathrm{CO})]^{*}, 426(9.5)\left[\mathrm{M}-5 \mathrm{CO}^{*+}, 398(19.0)\left[\mathrm{M}-6 \mathrm{CO}^{*}\right.\right.$, 374 (6.8) $[\mathrm{M}-(\mathrm{Cr}, 5 \mathrm{CO})]^{\circ}+, 346(100)[\mathrm{M}-(\mathrm{Cr}, 6 \mathrm{CO})]^{\circ}, 294$ (21.1) $[\mathrm{M}-(2 \mathrm{Cr}, 6 \mathrm{CO})]^{++}, 52(44.8)[\mathrm{Cr}]^{+} .-\mathrm{C}_{29} \mathrm{H}_{18} \mathrm{Cr}_{2} \mathrm{O}_{6}$ (566.45): calcd. C 61.49, H 3.20; found C 61.5, H 3.23 .

$\{9 H, 10 H-4 b, 9 a-([1,2]$ Benzenomethano $)$ indeno[1,2-a]indene $\}-$ $\alpha, \beta$-bis(tricarbonylchromium) (C): M.p. $202-205^{\circ} \mathrm{C}$ (dec.). - IR (THF): $\tilde{v}=1970 \mathrm{~cm}^{-1}$ (vs), 1961 (vs), 1890 (vs, CO). - MS, $m / z$ $(\%): 566(13.6)\left[\mathrm{M}^{\circ+}, 510(5.4)\left[\mathrm{M}-2 \mathrm{CO}^{{ }^{+}}, 482(30.6)[\mathrm{M}-\right.\right.$ $3 \mathrm{CO}]^{\circ+}, 454(6.8)[\mathrm{M}-4 \mathrm{CO}]^{\circ}, 430(4.1)[\mathrm{M}-(\mathrm{Cr}, 3 \mathrm{CO})]^{\circ+}$, $\left.426(21.8)[\mathrm{M}-5 \mathrm{CO}]^{\circ+}, 398(48.3)[\mathrm{M}-6 \mathrm{CO})\right]^{*+}, 374(3.4)$ $[\mathrm{M}-(\mathrm{Cr}, 5 \mathrm{CO})]^{\circ+}, 346(100)[\mathrm{M}-(\mathrm{Cr}, 6 \mathrm{CO})]^{\circ+}, 294(11.5)$
$[\mathrm{M}-(2 \mathrm{Cr}, 6 \mathrm{CO})]^{*}, 52(68.3)[\mathrm{Cr}]^{+} .-\mathrm{C}_{29} \mathrm{H}_{18} \mathrm{Cr}_{2} \mathrm{O}_{6}(566.45):$ calcd. C 61.49, H 3.20; found C 62.1, H 3.18 .

$\{9 \mathrm{H}, 10 \mathrm{H}-4 \mathrm{~b}, 9 \mathrm{a}-([1,2]$ Benzenomethano $)$ indeno[1,2-a]indene $\}$ $\alpha, \alpha, \alpha$-tris (tricarbonylchromium) (D): M.p. $202-203^{\circ} \mathrm{C}$ (dec.). - IR (THF): $\tilde{v}=1963 \mathrm{~cm}^{-1}$ (vs), 1891 (CO). - MS, $m / z$ (\%): 702 (10.8) $[\mathrm{M}]^{++}, 618(13.9)[\mathrm{M}-3 \mathrm{CO}]^{++}, 590(10.8)[\mathrm{M}-4 \mathrm{CO}]^{\circ+}, 566$ (7.1) $[\mathrm{M}-(\mathrm{Cr}, 3 \mathrm{CO})]^{*+}, 562(16.7)[\mathrm{M}-5 \mathrm{CO}]^{\circ+}, 534(19.7)$ $\left[\mathrm{M}-6 \mathrm{CO}^{\cdot+}, 510(3.4)[\mathrm{M}-(\mathrm{Cr}, 5 \mathrm{CO})]^{+}, 506(3.1)[\mathrm{M}-\right.$ $7 \mathrm{CO}]^{+}, 482(24.1)[\mathrm{M}-(\mathrm{Cr}, 6 \mathrm{CO})]^{++}, 478$ (4.4) $[\mathrm{M}-$ $8 \mathrm{CO}^{*+}, 450$ (5.4) $[\mathrm{M}-9 \mathrm{CO}]^{+}, 430$ (4.1) $[\mathrm{M}-(2 \mathrm{Cr}$, $6 \mathrm{CO})]^{*+}, 426(15.6)[\mathrm{M}-(\mathrm{Cr}, 8 \mathrm{CO})]^{*+}, 398(2.5)[\mathrm{M}-(\mathrm{Cr}$ $9 \mathrm{CO})]^{\cdot+}, 374(3.7)[\mathrm{M}-(2 \mathrm{Cr}, 8 \mathrm{CO})]^{\circ+}, 346(100)[\mathrm{M}-(2 \mathrm{Cr}$, $9 \mathrm{CO})]^{\cdot+}, 294(25.5)[\mathrm{M}-(3 \mathrm{Cr}, 9 \mathrm{CO})]^{+}, 52(92.4)[\mathrm{Cr}]^{+}$. $\mathrm{C}_{32} \mathrm{H}_{18} \mathrm{Cr}_{3} \mathrm{O}_{9}$ (702.5) calcd. C 54.71, H 2.58; found C 54.9, H 2.71.

is Dedicated to Professor Antonino Fava on the occasion of his 70 th birthday.

[1] Part 2: A. Ceccon, A. Gambaro, F. Manoli, A. Venzo, D. Kuck, P. Ganis, G. Valle, J. Chem. Soc., Perkin Trans. 2, 1992, 1111-1117. - Part. 1: See ref. ${ }^{[4]}$

${ }^{[2]}{ }^{[2 a]} \mathrm{H}$. W. Thompson, J. Org. Chem. 1968, 33, 621-625. - ${ }^{[2 \mathrm{~b}]} \mathrm{H}$. W. Thompson, Tetrahedron Lett. 1966, 6489-6492.

${ }^{[3]}$ D. Kuck in Quasicrystals, Networks, and Molecules of Fivefold Symmetry (Ed.: I. Hargittai), VCH, New York, NY, 1990, chapter 19.

${ }^{[4]}$ A. Ceccon, A. Gambaro, F. Manoli, A. Venzo, D. Kuck, T. E. Bitterwolf, P. Ganis, G. Valle, J. Chem. Soc., Perkin Trans. 2, 1991, $233-241$.

${ }^{[5]}$ D. Kuck, T. Lindenthal, A. Schuster, Chem. Ber. 1992, 125, $1449-1460$.

${ }^{[6]}$ B. Paisdor, D. Kuck, J. Org. Chem. 1991, 56, 5753- 5759.

[7] [7a] D. Kuck, B. Paisdor, H.-F. Grützmacher, Chem. Ber. 1987 , $120,589-595 .-{ }^{[7 \mathrm{~b}]}$ B. Paisdor, H.-F. Grützmacher, D. Kuck, Chem. Ber. 1988, 121, 1307-1313.

${ }^{[8][8 a]}$ D. Kuck, M. Seifert, Chem. Ber, 1992, 125, 1461-1469. ${ }^{[8 b]}$ D. Kuck, A. Schuster, R. A. Krause, J. Org. Chem. 1991, 56, 3472-3475. - ${ }^{[8 c]}$ A. Schuster, D. Kuck, Angew. Chem. 1991, 103, 1717-1720; Angew. Chem. Int. Ed. Engl. 1991, 30, $1699-1702$.

${ }^{[9]}$ The X-ray analysis of the free ligand (TRIP) shows $|\sigma|=22.8^{\circ}$; D. Kuck, A. Müller, H. Bögge, to be published.

${ }^{[10]}$ P. Lemmen, I. Ugi, Chem. Scr. 1987, 27, 297-301. 